\title{
Analisa Sistem Pemberian Pinjaman Anggota Koperasi Pada PT. Multi Megah Mandiri Menggunakan Metode Simple Additive Weighting (SAW)
}

\author{
Salwa Nurnika Tsabitah ${ }^{1}$, Mohammad Badrul $^{2}$ \\ Program Studi Sistem Informasi, STMIK Nusa Mandiri Jakarta \\ www.nusamandiri.ac.id \\ $\underline{{ }^{1} \text { salwasabita76@gmail.com, }}$ ²mohammad.mbl@nusamandiri.ac.id
}

\begin{tabular}{ccc}
\hline Diterima & Direvisi & Disetujui \\
$06-11-2020$ & $15-11-2020$ & $15-12-2020$ \\
\hline
\end{tabular}

\begin{abstract}
Abstrak - A cooperative is a legal entity based on the principle of kinship whose members consist of inviduals or legal entities with the aim of making the members prosperous. The problem that occurs is that the cooperative must consider the size or size of the loan to be given to the cooperative PT. Multi Megah Mandiri still needs assessment and matching with existing data. As well as the accumulation of loan dependents every month so that it hinders the decision to grant loans to its members. In this case a decision support system is used using the simple additive weighting (SAW) method for problem solving by evaluating based on predetermined criteria and weight values, besides that the method is capable of selecting the best alternative or ranking to make it easier to provide loans the SAW method is the best calculation example because it can find alternatives for each of its attributes. So after doing calculations using the simple additive weighting (SAW) method, you will get the result if there is the largest value, namely the selected value and the main value is given a loan.
\end{abstract}

\section{Keywords: Decision Support System, Simple Additive Weighting (SAW), Cooperative}

\begin{abstract}
Abstrak - Koperasi adalah badan hukum yang berdasarkan atas asas kekeluargaan yang anggotanya terdiri dari orang perorangan atau badan hukum dengan tujuan untuk mensejahterakan anggotanya. Permasalahan yang terjadi yaitu pihak koperasi harus mempertimbangkan besar atau kecilnya pinjaman yang akan diberikan. Pada koperasi PT. Multi Megah Mandiri masih perlu penilaian dan pencocokan dengan data yang ada, serta adanya penumpukan ajuan pinjaman pada setiap bulannya sehingga menghambat keputusan pemberian pinjaman pada anggotanya. Pada kasus ini digunakan sistem pendukung keputusan menggunakan metode simple additive weighting $(S A W)$ untuk pemecahan masalah dengan melakukan penilaian berdasarkan nilai kriteria dan bobot yang sudah ditentukan, selain itu metode tersebut mampu menyeleksi alternatif terbaik atau perangkingan untuk mempermudah dalam pemberian pinjaman. Metode SAW dijadikan sebuah contoh perhitungan yang paling bagus karena bisa mnemukan alternatif pada setiap atributnya. Jadi setelah melakukan perhitungan menggunakan metode simple additive weighting (SAW) akan mendapatkan hasil jika ada nilai yang terbesar yaitu nilai terpilih dan utama diberikan pinjaman.
\end{abstract}

Kata Kunci: Sistem Pendukung Keputusan, Simple Additive Weighting (SAW), Koperasi

\section{PENDAHULUAN}

\section{Latar Belakang Masalah}

Koperasi adalah badan hukum yang berdasarkan atas asas kekeluargaan yang anggotanya terdiri dari orang perorangan atau badan hukum dengan tujuan untuk mensejahterakan anggotanya. Seperti yang diungkapkan dalam UUD NRI 1945 Pasal 33 Ayat 1 koperasi merupakan bentuk demokrasi ekonomi, serta kemakmuran masyarakatlah yang diutamakan bukan kemakmuran seorang tegasnya, Mohammad Hata menyatakan bahwa koperasi adalah usaha bersama untuk memperbaiki nasib penghidupan ekonomi berdasarkan perekonomianya.(Mulya Firdausy, 2018)

Permasalahan yang terjadi yaitu pihak koperasi harus mempertimbangkan besar atau kecilnya pinjaman yang akan diberikan, dan seringkali terjadi kesalahan dalam pemberian pinjaman yang diberikan kepada calon nasabah karena penilaian yang dijadikan parameter tidak objektif dalam penentuan besar atau kecilnya kredit, hal ini disebabkan karena jumlah nasabah atau calon nasabah yang mengajukan pinjaman sangat banyak. Kesulitan lain pihak koperasi masih menggunakan cara sederhana dalam menghitung parameter kredit 
sehingga perhitungan data secara manual ini membutuhkan ini membutuhkan waktu yang lama dan berdampak pada lamanya waktu yang dibutuhkan dalam pengambilan keputusan. (Kasus et al., 2020)

Dari permasalahan diatas maka dibutuhkan pengembangan dengan perhitungan data dalam Sistem Pendukung Keputusan menggunakan metode SAW sebagai penunjang sistem atau pemecahan masalah dan dengan metode tersebut dapat melakukan penilaian secara lebih tepat, berdasarkan nilai kriteria dan bobot preferensi yang sudah ditentukan, agar mempermudah dalam memberikan keputusan pemberian pinjaman. Selain itu alasan penulis memilih metode tersebut karena merupakan metode penjumlahan berbobot, dapat melakukan penilaian secara lebih tepat dan mampu menyeleksi alternatif terbaik dari sejumlah alternatif yang ada.

\section{Identifikasi Masalah}

Berdasarkan uraian diatas dapat adanya identifikasi masalah pada Koperasi di PT.Multi Megah Mandiri yaitu:

1. Adanya penumpukan ajuan Peminjaman karena masih menggunakan cara sederhana dalam penilaian dan pencocokan data sehinga butuh waktu yang tidak sebentar.

\section{Maksud dan Tujuan}

Maksud :

1. Mempermudah pihak koperasi dalam menentukan pemberian pinjaman pada anggotanya, dengan menggunakan Metode SAW yang akan diterapkan.

\section{Sistem Pendukung Keputusan}

Sistem pendukung keputusan
diimplementasikan pada tahun 1960an oleh Massachusetts Institute of Technology kedalam bentuk sistem komputer interaktif. Dalam masa ini masih menggunakan komputer mainframe mahal untuk meneydiakan laporan terstruktur serta berkala bagi manajer. Pada tahun 1990an mulai adanya perkembangan tentang pemanfaatan data warehouse dan Online Analytical Processing (OLAP). Selama tahun tersebut terjadi pergeseran paradigma didalam sistem pendukung keputusan serta dikembangkan sistem kompleks yang menggabungkan teknologi basis data canggih dengan teknologi komputer yang telah menerapkan klien/server. Sistem ini banyak dipergunakan dalam berbagai area proses bisnis, peningkatan pada teknologi infrastruktur jaringan, teknologi berorientasi objek serta data warehouse dpat memberikan peluang kemampuan untuk pengembangan sistem pendukung keputusan. (Diana, 2018)

\section{Simple Additive Weighting (SAW)}

Metode Simple Additive Weighting (SAW) dijadikan sebuah contoh perhitungan yang paling bagus karena bisa menemukan alternatif pada setiap atributnya. Kemudian tahap selanjutnya dibuatlah perangkingan yang akan memilih alternatif terbaik, sehingga metode ini dapat diartikan sebagai sistem penjumlahan berbobot. Dalam perhitungan menggunakan metode ini dibutuhkan normalisasi dari data asli ke skala, selanjutnya dibandingkan pada semua rating disetiap alternatif. (Limbong, 2020)

$$
\mathrm{r}_{\mathrm{i}}{ }^{\mathrm{j}}\left\{\begin{array}{l}
\frac{X_{\mathrm{i}}^{\mathrm{j}}}{\max x_{\mathrm{i}}{ }^{\mathrm{j}}} \\
\frac{\min x_{\mathrm{i}}^{\mathrm{j}}}{x_{\mathrm{i}}^{\mathrm{j}}}
\end{array}\right.
$$

Keterangan :

$\mathrm{r}_{\mathrm{i}}^{\mathrm{j}} \quad$ : rating kinerja ternormalisasi

$\mathrm{X}_{\mathrm{i}}{ }^{\mathrm{j}} \quad$ : nilai atribut yang dimiliki setiap kriteria

maxxij : nilai terbesar dari setiap kriteria

minxij : nilai terkecil dari setiap kriteria

benefit : jika nilai terbesar ialah terbaik

cost : jika nilai terkecil ialah terbaik

Rij rating kinerja ternormalisasi dari alternatif $\mathrm{A}$, dalam atribut $\mathrm{Ci}$ ' $\mathrm{i}=1,2, \ldots, \mathrm{m} \mathrm{j}=1,2, . \mathrm{n}$ Nilai prefensi kepada alternatif $(\mathrm{v})$ :

$$
\mathrm{V}_{\mathrm{i}}=\sum_{\mathrm{j}={ }_{1}}^{\mathrm{n}} w^{\mathrm{j}} r_{\mathrm{i}}^{\mathrm{j}}
$$

Keterangan :

$\mathrm{V}_{\mathrm{i}}$ = rangking untuk setiap alternatif $(\mathrm{A})$

$\mathrm{W}^{\mathrm{j}}=$ nilai bobot dari setiap kriteria $(\mathrm{C})$

$\mathrm{r}_{\mathrm{i}}^{\mathrm{j}}=$ nilai rating kinerja ternormalisasi

Nilai V yang lebih besar menunjukan alternatif $\mathrm{A}$ terpilih dari metode SAW sebagai berikut :

a. Menentukan rating kecocokan alternatif pada setiap kriteria serta dinyatakan dalam bentuk matriks

b. Memberikan bobot kerja kinerja (W)

c. Menghasilkan nilai matriks yang ternormalisasi (R). (Limbong, 2020)

\section{METODE PENELITIAN}

\section{Tahapan Penelitian}

Dalam tahapan penelitian yang mencakup langkahlangkah didalam kerangka pikiran tersebut dapat digambarkan dalam bentuk flowchart sebagai berikut : 


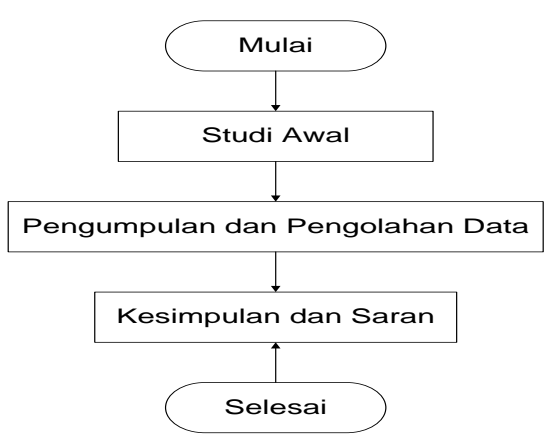

Sumber : Algoritma \& Pemrograman (Anggrawan, 2018)

\section{Gambar 1 : Tahapan Penelitian}

Dari masing-masing langkah diatas dapat diuraikan sebagai berikut :

1. Studi Awal

Langkah awal dalam penelitian ini adalah mencari serta mempelajari masalah yang sudah kita tentukan untuk diteliti, setelah itu peneliti menentukan latar belakang, ruang lingkup, dan untuk mencapai tujuan yang diharapkan perlu mempelajari beberapa literatur yang terkait dengan permasalahan dan bagaimana mencari solusinya.

2. Pengumpulan dan Pengolahan Data

Dalam proses pengumpulan data yang diperlukan penulis adalah menanyakan secara langsung tentang masalah yang dihadapi khususnya tentang pemberian pinjaman koperasi. Pada tahap pengolahan data yang dilakukan pertama ialah mengidentifikasikan masalah yang ada kemudian mendeskripsikan masalah tersebut untuk mendapatkan solusi.

3. Kesimpulan dan Saran

Pada tahap ini penulis akan memberikan kesimpulan dari penelitaian yang dilakukan serta memberikan saran berdasarkan penelitian terhadap proses pemberian pinjaman koperasi pada PT. Multi Megah Mandiri.

\section{Instrumen Penelitian}

Dalam tahap ini penulis telah menentukan data apa saja yang diperlukan dalam penelitian. Ada dua jenis data berdasarkan data perolehannya yaitu :

1. Data Primer

Data Primer yang digunakan dalam penelitian bersumber dari proses wawancara atau tanya jawab kepada bendahara koperasi yang terlibat dalam penelitian sebagai berikut :
a. Data observasi dan wawancara kepada bendahara koperasi
b. Data anggota koperasi
c. Data langsung dari perusahaan

2. Data Sekunder

Data yang diperoleh dalam data sekunder berasal dari studi pustaka atau teori pendukung yang berupa buku dan jurnal terdahulu.

\section{Metode Pengumpulan Data}

a. Observasi

Penulis mengamati secara langsung proses pemberian pinjaman koperasi yang masih menggunakan cara sederhana dalam prosesnya, sehingga peneliti ingin membantu pihak koperasi dalam pemberian pinjaman koperasi.

b. Wawancara

Pada tahap ini peneliti memberikan bebrapa pertanyaan kepada Ibu Sugiyem selaku bendahara koperasi yang secara langsung memproses pemberian pinjaman dengan tatap muka dan mendengarkan secara langsung.

c. Studi Pustaka

Merupakan bahan pembelajaran terhadap kasus yang sama peneliti melalukan peneliti kepustakaan melalui buku referensi, jurnal ilmiah dan dari instansi yang berkaitan.

\section{Populasi dan Sampel Penelitian}

Populasi dalam penelitian ini adalah jumlah anggota koperasi sebanyak 65 anggota. slovin.

Dalam penelitian sample menggunakan rumus

$$
\begin{aligned}
& \mathrm{n}=\frac{N}{1+N(d)^{2}} \\
& \text { keterangan : } \\
& \mathrm{n}=\text { sampel } \\
& \mathrm{N}=\text { populasi } \\
& \mathrm{d}=\text { tingkat kesalahan }(1 \%, 5 \%, \text { atau } 10 \%)
\end{aligned}
$$

jika diterapkan rumus slovin dengan tingkat kepercayaan $95 \%$ dan tingkat error 5\% maka perhitunganya sebagai berikut :

$$
\begin{aligned}
\mathrm{n} & =\frac{65}{1+65(0.05)^{2}} \\
& =\frac{65}{1+(65 \times 0,0025)^{2}} \\
& =\frac{65}{1+0,1625} \\
& =\frac{65}{1,1625} \\
& =55,914 \quad(56 \text { anggota })
\end{aligned}
$$

Jadi sampel penelitian yang diambil dari perhitungan menggunakan rumus slovin hasilnya adalah 56 anggoota.

\section{Metode Analisis Data}

Hal ini merupakan hal penting dan sangat mempengaruhi hasil penelitian. Jika metode yang digunakan sesuai dengan objek penelitian maka hasilnya akan diterima.

\section{Tabel Kriteria 1}

\begin{tabular}{|c|}
\hline Keaktifan \\
\hline Besar pinjaman \\
\hline Jangka waktu \\
\hline
\end{tabular}

Sumber : Koperasi PT.Multi Megah Mandiri 


\section{HASIL DAN PEMBAHASAN}

Setelah melakukan penelitian terhadap Koperasi pada PT. Multi Megah Mandiri dapat dilakukan analisis data yang khusus dilakaukan pada pemberian pinjaman koperasi berikut tahapannya.

\section{Data Anggota Koperasi}

Langkah pertama dalam penelitian adalah mencatat data anggota periode 2020 yang sudah tersedia untuk dijadikan data saat akan memberikan pinjaman.

Tabel 2

Tabel Anggota Koperasi

\begin{tabular}{|c|c|c|c|}
\hline NO & $\begin{array}{c}\text { NAMA } \\
\text { ANGGOTA }\end{array}$ & DEPT & $\begin{array}{c}\text { MASUK } \\
\text { ANGGOTA }\end{array}$ \\
\hline 1 & Ahmad Yani & Marketing & 01 Mei 2013 \\
\hline 2 & Afifatun ni'mah & Acc & 01 Jan 2013 \\
\hline 3 & Agung Prabowo & Teknisi & 01 Sep 2011 \\
\hline 4 & Aman Kurnia & Teknisi & 01 Aug 2011 \\
\hline 5 & Amid & Sopir & 01 Feb 2014 \\
\hline 6 & Ari Muharom & Acc & 01 Jan 2016 \\
\hline 7 & Asnawati & Kasir & 01 Nov 2012 \\
\hline 8 & Badru Jaman & Marketing & 01 Mar 2014 \\
\hline 9 & Darma Kusuma & Teknisi & 01 Jan 2015 \\
\hline 10 & $\begin{array}{ll}\text { Dedi } & \text { Catur } \\
\text { Widyanto } & \end{array}$ & Teknisi & 01 Okt 2011 \\
\hline 11 & Dedi Mulyadi & KK Knitting & 01 Jan 2016 \\
\hline 12 & Desti Ratnasari & $\begin{array}{l}\text { Sales } \\
\text { Marketing }\end{array}$ & 01 Nov 2014 \\
\hline 13 & Dewi Saraswati & Acc & 01 Jan 2012 \\
\hline 14 & Dian & Marketing & 01 Nov 2013 \\
\hline 15 & Diki Hidayat & Cuci Celup & 01 Jul 2016 \\
\hline 16 & Dwi Hariyani & Marketing & 01 Okt 2013 \\
\hline 17 & Eko Sumaryono & Teknisi & 01 Jan 2012 \\
\hline 18 & Eny Suprihatin & Marketing & 01 Jan 2015 \\
\hline 19 & Erni Ayudiah & Marketing & 01 Des 2015 \\
\hline 20 & Erni Handayani & Marketing & 01 Jan 2016 \\
\hline 21 & $\begin{array}{ll}\text { Erol } & \text { Haikal } \\
\text { Adam } & \\
\end{array}$ & Teknisi & 01 Jul 2011 \\
\hline 22 & Febry Aryanti & Marketing & 01 Jan 2014 \\
\hline 23 & $\begin{array}{l}\text { Gunawan } \\
\text { Thamrin }\end{array}$ & $\begin{array}{l}\text { Sales } \\
\text { Marketing }\end{array}$ & 01 Jan 2016 \\
\hline 24 & Harum Sari & Staff SDM & 01 Okt 2014 \\
\hline 25 & $\begin{array}{ll}\text { Indra } & \text { Jaya } \\
\text { Kusuma } & \\
\end{array}$ & Marketing & 01 May 2013 \\
\hline 26 & $\begin{array}{l}\text { Inggan } \\
\text { Sulaeman }\end{array}$ & Marketing & 01 Jan 2016 \\
\hline 27 & Irnovan Tenang & K Counter & 01 Jan 2014 \\
\hline 28 & Istiqomah & $\begin{array}{l}\text { Staff } \\
\text { Gudang }\end{array}$ & 01 Okt 2013 \\
\hline 29 & Jakalesmana & $\begin{array}{l}\text { MD } \\
\text { Jabotabek }\end{array}$ & 01 Feb 2016 \\
\hline 30 & Junaedi Anwar & Teknisi & 01 Nov 2013 \\
\hline 31 & Kosasih Saputra & KK Teknissi & 01 Jan 2011 \\
\hline 32 & $\begin{array}{ll}\text { Lastari } & \text { Tjahja } \\
\text { Sulistiati } & \\
\end{array}$ & Marketing & 01 Aug 2011 \\
\hline 33 & Lestariningsih & Marketing & 01 Okt 2013 \\
\hline 34 & Lili & Staf Acc & 01 Aug 2016 \\
\hline 35 & Linda Apriyani & Acc & 01 Jan 2012 \\
\hline
\end{tabular}

\begin{tabular}{|c|l|l|l|}
\hline 36 & Lisa & PPIC & 01 Mar 2013 \\
\hline 37 & Lusiana & Staff Acc & 01 Nov 2014 \\
\hline 38 & M. Fadian & Teknisi & 01 jan 2014 \\
\hline 39 & M. Hadi Purnomo & $\begin{array}{l}\text { Staff } \\
\text { Designer }\end{array}$ & 01 Nov 2013 \\
\hline 40 & Marlinda & Staff Gudang & 01 Sep 2016 \\
\hline 41 & Miswantoro & Teknisi & 01 Nov 2013 \\
\hline 42 & Muslim & Teknisi & 01 Jan 2015 \\
\hline 43 & Nana Kusbiana & Staf Designer & 01 Feb 2016 \\
\hline 44 & Nasruloh & Marketing & 01 May 2013 \\
\hline 45 & Nawin & Kurir & 01 Feb 2013 \\
\hline 46 & Neni Suryani & Acc & 01 Jun 2011 \\
\hline 47 & Partini & Staff Gudang & 01 Jun 2011 \\
\hline 48 & Pujiono & Teknisi & 01 Jul 2011 \\
\hline 49 & $\begin{array}{l}\text { Riska } \\
\text { Yuliarelawati }\end{array}$ & Staff Gudang & 01 Sep 2016 \\
\hline 50 & Rita Widiastuti & Marketing & 01 Okt 2011 \\
\hline 51 & Robet Sarumaha & Marketing & 01 Jan 2016 \\
\hline 52 & Rudi Syahril & KK Gd bku & 01 Jan 2011 \\
\hline 53 & Samsul Bachry & Marketing & 01 May 2013 \\
\hline 54 & Saripudin & Teknisi & 01 Aug 2011 \\
\hline 55 & Siti Mukadimatul & Acc & 01 Jun 2011 \\
\hline 56 & Sudarmanto & $\begin{array}{l}\text { Staff } \\
\text { Designer }\end{array}$ & 01 Nov 2013 \\
\hline
\end{tabular}

Sumber : Koperasi PT.Multi Megah Mandiri (2020)

\section{Kriteria dan Nilai Bobot}

Tabel 3

Kriteria

\begin{tabular}{|c|c|}
\hline C1 & Besar Pinjaman \\
\hline C2 & Keaktifan \\
\hline C3 & Jangka Waktu \\
\hline
\end{tabular}

Sumber : Koperasi PT. Multi Megah Mandiri

Kemudian setelah kriteria sudah diketahui maka akan ditentukan nilai bobot pada setiap kriteria yang dimana jika dijumlahkan hasilnya $100 \%$ berikut tabelnya.

Tabel 4

\section{Nilai Bobot}

\begin{tabular}{|c|c|}
\hline Kriteria & Nilai \\
\hline $\begin{array}{c}\text { Besar Pinjaman } \\
(\mathrm{C} 1)\end{array}$ & 0.5 \\
\hline Keaktifan $(\mathrm{C} 2)$ & 0.3 \\
\hline Jangka Waktu (C3 & 0.2 \\
\hline Jumlah & $100 \%$ \\
\hline
\end{tabular}

Sumber : Sistem Pendukung Keputusan Teori dan Implementasi (Latif et al., 2018)

\section{Data Peminjam}

Data peminjam pada periode Juli 2020 hanya ada empat anggota yang meminjam, berikut adalah data peminjam. 
Tabel 5

Data Peminjam

\begin{tabular}{|c|c|c|c|c|}
\hline $\begin{array}{l}\mathrm{N} \\
\mathrm{O}\end{array}$ & $\begin{array}{c}\text { NAMA } \\
\text { ANGGOT } \\
\text { A }\end{array}$ & $\begin{array}{c}\text { BESAR } \\
\text { PINJAMA } \\
\mathrm{N} \\
(\mathrm{C} 1) \\
\end{array}$ & $\begin{array}{c}\text { KEAKTIFA } \\
\text { N } \\
(\mathrm{C} 2)\end{array}$ & $\begin{array}{c}\text { JANGK } \\
\text { A } \\
\text { WAKT } \\
\text { U (C3) } \\
\end{array}$ \\
\hline 1 & $\begin{array}{l}\text { Kosasih } \\
\text { Saputra }\end{array}$ & 4.000 .000 & $9 \mathrm{TH}$ & 10 kali \\
\hline 2 & $\begin{array}{l}\text { Rudy } \\
\text { Syahril }\end{array}$ & 7.000 .000 & $9 \mathrm{TH}$ & 10 kali \\
\hline 3 & Saripudin & 7.000 .000 & $9 \mathrm{TH}$ & 10 kali \\
\hline 4 & $\begin{array}{l}\text { Sudarmant } \\
\text { o }\end{array}$ & 6.000 .000 & $7 \mathrm{TH}$ & 10 kali \\
\hline
\end{tabular}

Sumber : Koperasi PT. Multi Megah Mandiri

\section{Perhitungan}

Perhitungan dalam penelitian ini untuk menentukan pemberian pinjaman koperasi pada PT. Multi Megah Mandiri yang pertama setelah mengetahui bobot maka selanjutnya adalah membuat tabel rating kecocokan sebagai berikut:

Tabel 6

Rating Kecocokan

\begin{tabular}{|c|c|c|c|}
\hline \multirow{2}{*}{$\begin{array}{c}\text { Nama } \\
\text { Peminjam }\end{array}$} & \multicolumn{3}{|c|}{ Kriteria } \\
\cline { 2 - 4 } & $\mathbf{C 1}$ & $\mathbf{C 2}$ & $\mathbf{C 3}$ \\
\hline Kosasih Saputra & 1 & 1 & 1 \\
\hline Rudy Syahril & 0,57 & 1 & 1 \\
\hline Saripudin & 0,57 & 1 & 1 \\
\hline Sudarmanto & 0,67 & 0,78 & 1 \\
\hline
\end{tabular}

Sumber : Konsep Data Mining Sistem Pendukung Keputusan (Nofriansyah, 2015)

Dari tabel diatas maka matriks $\mathrm{X}$ yang dibuat berdasarkan tabel diatas dengan rumus sebagai berikut :

$$
\begin{aligned}
& \mathrm{X}=\left(\begin{array}{cccc}
\mathrm{x}_{11} & \mathrm{x}_{12} & \ldots & \mathrm{x}_{1}^{\mathrm{j}} \\
\ldots & \ldots & \ldots . & \ldots \\
\ldots . & \ldots . & . . & \ldots \\
\mathrm{x}_{\mathrm{i} 1} & \mathrm{x}_{12} & : & \mathrm{x}_{\mathrm{j} j}
\end{array}\right) \\
& \mathrm{X}=\left(\begin{array}{cccc}
1 & 1 & 1 \\
0,57 & 1 & & 1 \\
0,57 & 1 & 1 \\
0,67 & 0,78 & 1
\end{array}\right)
\end{aligned}
$$

Setelah diubah menjadi matriks, kemudian langkah selanjutnya adalah menormalisasi matriks tersebut dengan rumus dibawah ini : (Limbong, 2020)

$$
\mathrm{r}_{\mathrm{i}}^{\mathrm{j}}\left\{\begin{array}{l}
\frac{X_{\mathrm{i}}^{\mathrm{j}}}{\max x_{\mathrm{i}}^{\mathrm{j}}} \\
\frac{\min x_{\mathrm{i}}^{\mathrm{j}}}{x_{\mathrm{i}}^{\mathrm{j}}}
\end{array}\right.
$$

Keterangan :

$r_{i}{ }^{j} \quad$ : rating kinerja ternormalisasi
$\mathrm{X}_{\mathrm{i}}{ }^{\mathrm{j}} \quad$ : nilai atribut yang dimiliki setiap kriteria

maxxij : nilai terbesar dari setiap kriteria minxij : nilai terkecil dari setiap kriteria benefit : jika nilai terbesar ialah terbaik cost : jika nilai terkecil ialah terbaik

\section{C1 Besar Pinjaman}

$r_{11}=\frac{1}{\max (1,0,57,0,57,0,67)}=\frac{1}{1}=1$
$r_{12}=\frac{0,57}{\max (1,0,57,0,57,0,67)}=\frac{0,57}{1}=0,57$
$r_{13}=\frac{0,57}{\max (1,0,57,0,57,0,67)}=\frac{0,57}{1}=0,57$
$r_{14}=\frac{0,67}{\max (1,0,57,0,57,0,67)}=\frac{0,67}{1}=0,67$

\section{C2 Keaktifan}

$$
\begin{aligned}
& \mathrm{r}_{21}=\frac{1}{\max (1,1,1,0,78)}=\frac{1}{1}=1 \\
& \mathrm{r}_{22}=\frac{1}{\max (1,1,1,0,78)}=\frac{1}{1}=1 \\
& \mathrm{r}_{23}=\frac{1}{\max (1,1,1,0,78)}=\frac{1}{1}=1 \\
& \mathrm{r}_{24}=\frac{0,78}{\max (1,1,1,0,78)}=\frac{0,78}{1}=0,78
\end{aligned}
$$

\section{C3 Jangka Waktu}

$$
\begin{aligned}
& r_{31}=\frac{1}{\max (1,1,1,1)}=\frac{1}{1}=1 \\
& r_{32}=\frac{1}{\max (1,1,1,1)}=\frac{1}{1}=1 \\
& r_{33}=\frac{1}{\max (1,1,1,1)}=\frac{1}{1}=1 \\
& r_{34}=\frac{1}{\max (1,1,1,1)}=\frac{1}{1}=1
\end{aligned}
$$

Hasil dari perhitungan diatas maka akan dimasukan kedalam tabel dibawah ini yaitu :

Tabel 7

Hasil Normalisasi Matriks X

\begin{tabular}{|l|c|c|c|}
\hline Nama Peminjam & C1 & C2 & C3 \\
\hline Kosasih Saputra & 1 & 1 & 1 \\
\hline Rudy Syahril & 0,57 & 1 & 1 \\
\hline Saripudin & 0,57 & 1 & 1 \\
\hline Sudarmanto & 0,67 & 0,78 & 1 \\
\hline
\end{tabular}

Kemudian hasil dari tabel normalisasi maka dapat dibentuk kedalam matriks ternomalisasi (R) dengan rumus sebagai berikut dan angka yang diperolehnya:

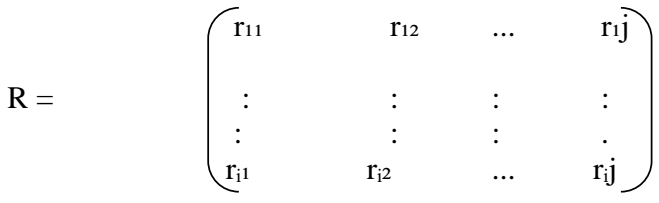

$$
\begin{aligned}
& \mathrm{R}=\left(\begin{array}{ccc}
1 & 1 & 1 \\
0,57 & 1 & 1 \\
0,57 & 1 & 1 \\
0,67 & 0,78 & 1
\end{array}\right)
\end{aligned}
$$

http://ejournal.bsi.ac.id/ejurnal/index.php/infortech 
Kemudian setelah diketahui hasil dari perhitungan normalisasi maka langkah akhir yaitu perangkingan yang diperoleh dari penjumlahan perkalian matriks ternormalisasi (R) dengan bobot setiap kriteria, sehingga nilai rangking yang terbesar adalah yang terpilih pertama dan terbaik dengan rumus sebagai berikut :

$$
\mathrm{V}_{\mathrm{i}}=\sum_{\mathrm{j}={ }_{1}}^{\mathrm{n}} w^{\mathrm{j}} r_{\mathrm{i}}^{\mathrm{j}}
$$

Keterangan :

$$
\begin{aligned}
& \mathrm{V}_{\mathrm{i}}=\text { rangking untuk setiap alternatif }(\mathrm{A}) \\
& \mathrm{W}^{\mathrm{j}}=\text { nilai bobot dari setiap kriteria }
\end{aligned}
$$

$$
\mathrm{r}_{\mathrm{i}}^{\mathrm{j}}=\text { nilai rating kinerja ternormalisasi }
$$

dibawah ini adalah cara perhitungan dan nilai yang diperoleh :

$$
\begin{aligned}
\mathrm{V}_{1} & =(1.0,5)+(1.0,3)+(1.0,2) \\
& =0,5+0,3+0,2+=1 \\
\mathrm{~V}_{2} & =(0,57 \cdot 0,5)+(1.0,3)+(1.0,2) \\
& =0,285+0,3+0,2=0,79 \\
\mathrm{~V}_{3} & =(0,57.0,5)+(1.0,3)+(1.0,2) \\
& =0,285+0,3+0,2=0,79 \\
\mathrm{~V}_{4} & =(0,67.0,5)+(0,78.0,3)+(1.0,2) \\
& =0,335+0,234+0,2=0,77
\end{aligned}
$$

Tabel IV.7

Perangkingan

\begin{tabular}{|c|c|}
\hline Nama Peminjam & Rangking \\
\hline Kosasih Saputra & 1 \\
\hline Rudy Syahril & 0,79 \\
\hline Saripudin & 0,79 \\
\hline Sudarmanto & 0,77 \\
\hline
\end{tabular}

Hasil akhir dari perhitungan perangkingan maka terlihat nilai rangking yang terbesar Kosasih Saputra adalah nilai yang terpilih dan utama untuk diberikan pinjaman koperasi.

\section{KESIMPULAN}

Berdasarkan Penelitian yang telah dilakssanakan maka dapat diambil kesimpulan bahwa :

1. Penerapan sistem pendukung keputusan menggunakan metode SAW dapat mempermudah pihak koperasi dalam menentukan pemberian pinjaman.

2. Memberikan solusi berdasarkan kriteria yang sudah ditentukan, untuk menentukan prioritas dan utama peminjam dalam pemberian pinjaman koperasi.

\section{REFERENSI}

Anggrawan, A. (2018). Algoritma \& Pemrograman (A. Pramesta (ed.)). Penerbit ANDI. https://books.google.co.id/books?id=ymZ-

DwAAQBAJ\&printsec $=$ frontcover $\& \mathrm{dq}=$ flowc
hart+adalah\&hl=id\&sa=X\&ved=0ahUKEwjrs rur7LjpAhUTWX0KHUgvC9kQ6wElPzAl\#v

$=$ onepage $\& \mathrm{q}=$ flowchart adalah $\& \mathrm{f}=$ false

Diana. (2018). Metode \& Aplikasi Sistem Pendukung Keputusan. CV Budi Utama. https://book.google.co.id/books?id=nJSEDwA AQBAJ\&prinsec $=$ frontcover $\& \mathrm{dq}=$ sistem + pen dukung+keputusan \&hl=id\&sa $=X \& v e d=0 a h U$ KEwib76Gw9vvoAhVD7XMBHfeUD6wQ6A EICDAA\#v=onepage $\& \mathrm{q}=$ sistem pendukung keputusan $\& \mathrm{f}=$ false

Kasus, S., Kemuning, K., \& Cabang, P. (2020). Sistem pendukung keputusan untuk kelayakan pemberian kredit dengan metode fuzzy tsukamoto (studi kasus koperasi kemuning persada cabang bandung). 14, 38-45.

Latif, L. A., Jamil, M., \& Abbas, S. H. (2018). SISTEM PENDUKUNG KEPUTUSAN TEORI DAN IMPLEMENTASI. DEEPUBLISH. https://books.google.co.id/books?id=TeBjDw AAQBAJ\&pg=PA3\&dq=tujuan+sistem + pend ukung+keputusan \&hl=id\&sa=X\&ved=0ahUK Ewi198-

kyKTpAhUi8HMBHesPDlwQ6wElPjAH\#v=o nepage $\& q=$ tujuan sistem pendukung keputusan $\& \mathrm{f}=$ false

Limbong, T. (2020). Sistem Pendukung Keputusan Metode \& Implementasi. Yayasan Kita Menulis.

https://books.google.co.id/books?id=6FnYDw AAQBAJ\&printsec $=$ frontcover $\& d q=$ sistem $+p$ endukung+keputusan $\& \mathrm{hl}=\mathrm{jv} \& \mathrm{sa}=\mathrm{X} \& \mathrm{ved}=0 \mathrm{ah}$ UKEwjIo7Wb_fvoAhX47XMBHSBCB04Q6 wEIWTAF\# $\mathrm{v}=$ onepage $\& \mathrm{q}=$ sistem pendukung keputusan $\& \mathrm{f}=$ false

Mulya Firdausy, C. (2018). KOPERASI DALAM SISTEM PEREKONOMIAN DI INDONESIA (C. Mulya Firdausy (ed.)). Buku OBOR. https://books.google.co.id/books?id=9POiDw AAQBAJ\&pg=PA42\&dq=koperasi+adalah\&h $1=$ id\&sa $=$ X\&ved=0ahUKEwih6ov1u_oAhVYdCsKHc7dBjwQ6AEIHTAD\#vonepage $\& \mathrm{q}=$ koperasi adalah $\& \mathrm{f}=$ false

Nofriansyah, D. (2015). KONSEP DATA MINING SISTEM PENDUKUNG KEPUTUSAN. DEEPUBLISH. 